\title{
Produção animal e comportamento ingestivo de bovinos em sistema integrado de produção agropecuária
}

\author{
Denise Adelaide Gomes Elejalde', André Brugnara Soares², Regis Luis Missio', Tangriani Simioni Assmann², \\ Angela Bernardon ${ }^{3}$ e Angélica Caroline Zatta ${ }^{4}$
}

\begin{abstract}
Resumo - Este estudo objetiva avaliar, em sistema integrado de produção agropecuária, o desempenho e a produção animal em pastagem de aveia-preta e azevém. O delineamento experimental utilizado foi o de blocos ao acaso em esquema fatorial, com três repetições. Os fatores foram duas alturas do pasto $(10$ e $25 \mathrm{~cm})$ mantidas sob pastejo com lotação contínua e taxa de lotação variável, além de passarem por duas épocas de adubação nitrogenada no sistema (NP - adubação nitrogenada feita na pastagem, no outono e NG - adubação nitrogenada feita na lavoura - cultura de grãos). A quantidade total de nutrientes aplicados por ano foi a mesma para todos os tratamentos. A aplicação do nitrogênio (ureia $-45 \% \mathrm{~N}$ ) na pastagem indicou aumento no valor nutritivo, oferta e massa de forragem, assim como na capacidade de suporte, sem alterar o desempenho animal, resultando em maior produção animal por unidade de área. A menor altura de dossel condicionou menor massa de forragem, maior tempo diurno de pastejo e menor tempo diurno de ruminação.
\end{abstract}

Termos para indexação: Adubação de sistema; Adubação nitrogenada; Avena strigosa Schreb; Intensidade de pastejo; Lolium multiflorum Lam.

\section{Animal production and ingestive behavior in an integrated crop-livestock system}

\begin{abstract}
This trial aimed to assess animal performance and production in a mixture pasture of black oat and annual ryegrass in an integrated crop-livestock system by means of a $2 \times 2$ factorial experiment replicated in three randomized blocks. The plots consisted of two canopy heights $(10$ and $25 \mathrm{~cm})$ kept by continuous grazing and submitted to two-nitrogen fertilization (NP - nitrogen applied on pasture in autumn time; and NG - nitrogen applied on corn crop in springtime). The total amount of nutrients applied over the year was the same for all treatments. Forage nutritive value, herbage allowance, forage mass, and pasture carrying capacity increased with nitrogen application (urea $-45 \% \mathrm{~N}$ ) on pasture, with no effect on animal performance, resulting in higher animal production per area. Lower sward canopy height led to lower forage mass, longer grazing diurnal time, and shorter rumination diurnal time.
\end{abstract}

Index terms: Fertilization system; Avena strigosa Schreb; Grazing intensity; Lolium multiflorum Lam; Nitrogen fertilization.

\section{Introdução}

A aveia-preta (Avena strigosa Schreb.) e o azevém anual (Lolium multiflorum Lam) são forrageiras usadas em consórcio, encontradas facilmente no sul do Brasil para compor as pastagens de inverno, seja em integração lavourapecuária ou não. A consorciação destas espécies proporciona maiores períodos de utilização em função da diferença de velocidade de estabelecimento e estágio de crescimento entre as duas espécies, sendo que o azevém possui um ciclo mais tardio que a aveia (FERRAZZA et al., 2013).
Estudos demostram que modelos de produção que utilizam bovinos para pastejo indicam que a presença do animal não é prejudicial às produtividades das culturas agrícolas posteriores (PETERSON et al., 2020). Isto se deve à maior produção de biomassa do dossel forrageiro quando submetido à desfolha (Mc NAUGHTON, 1983) pela ciclagem dos nutrientes, onde o animal retira pelo pasto os nutrientes que necessita e os repõe por meio das fezes e da urina (CARPINELLI et al., 2021), além da camada superficial que, devido aos dejetos dos animais, se torna rica em matéria orgânica incrementando o rendimento das culturas (COSTA et al., 2014). Na prática, a maioria das áreas destinadas à produção de grãos não tem pastejo de forma intercalada no tempo. Entretanto, agricultores vêm aderindo ao sistema integrado de produção e mantendo a área produtiva o ano todo, o que proporciona diversificação e aumento de renda. 0 correto manejo da pastagem, em termos de intensidade de pastejo e adubação, parece ser um dos principais fatores determinantes do sucesso de um sistema integrado de produção agropecuária. Assim, o estudo objetivou avaliar o efeito da época da fertilização nitrogenada (na lavoura ou

2 Engenheiro-agrônomo, Dr., Departamento de Ciências Agrárias, UTFPR, Pato Branco, e-mail: soares@utf pr.edu.br, tangrisimioni@gmail.com

${ }^{3}$ Engenheira-agrônoma, Dra., Universidade Estadual de Santa Catarina (Udesc), Lages, e-mail: angela.agro@yahoo.com.br

${ }^{4}$ Engenheira-agrônoma, Msc., Departamento de Ciências Agrárias, UTFPR, Pato Branco, e-mail: angelica_zatt a@hotmail.com 
na pastagem) em duas alturas de pasto (10 e $25 \mathrm{~cm}$ ) sobre o comportamento ingestivo, desempenho e produção animal de novilhos em pastagem de aveia preta e azevém em sistema integrado de produção agropecuária.

\section{Materiais e métodos}

O trabalho foi conduzido na Agropecuária Pacheco, no município de Abelardo Luz, em Santa Catarina, no sul do Brasil ( $26^{\circ} 31^{\prime} \mathrm{S}, 51^{\circ} 35^{\prime} \mathrm{W}, 850 \mathrm{~m}$ de altura) e trata-se de um experimento de longo prazo em sistema integrado de produção agropecuária (SIPA) usando plantio direto desde 2012. O clima da região é classificado Cfb (subtropical mesotérmico úmido) com verões quentes e invernos frios conforme a classificação de Köppen. Precipitação média anual de $2200 \mathrm{~mm}$, temperatura média anual de $17^{\circ} \mathrm{C}$. O solo é classificado como Latossolo Bruno Distroférrico Típico de textura muito argilosa, com Horizonte $A$ proeminente.

O experimento iniciou com o pastejo de Sorghum bicolor no verão de 2012/2013 seguido pelo pastejo de aveia-preta (Avena strigosa Schreb.) no inverno de 2013. Posteriormente, o miIho (Zea mays L.) foi plantado para produção de grãos, no verão de 2013/2014. Este trabalho refere-se à pastagem após o milho, no inverno de 2014. Após a colheita do grão de milho, o campo foi dessecado com aplicação de 1,33l ha-1 de glifosato em 29 de março de 2014. Logo, a mistura de aveia-preta 'BRS 139' (100kg ha-1) e azevém 'Barjumbo' ( $25 \mathrm{~kg} \mathrm{ha}^{-1}$ ) foi semeada em 3 de abril de 2014 em sistema plantio direto, com espaçamento de $0,17 \mathrm{~m}$ entre linhas. $\mathrm{Na}$ ocasião, a área foi fertilizada com $7 \mathrm{~kg}$ de $\mathrm{N}$ ha-1, 70,4kg de $\mathrm{P}_{2} \mathrm{O}_{5}$ ha $^{-1} \mathrm{e}$ $63,4 \mathrm{~kg}$ de $\mathrm{K}_{2} \mathrm{O} \mathrm{ha}^{-1}$ de N-P-K formulado, baseando-se na análise de solo (0$20 \mathrm{~cm}$ ) e nas recomendações da Comissão de Química e Fertilidade do Solo dos estados do RS e SC (CQFS, 2016).

O delineamento experimental foi blocos ao acaso, com 3 repetições e os tratamentos foram arranjados em es- quema fatorial $2 \times 2$, sendo duas alturas de manejo da pastagem $(25$ e $10 \mathrm{~cm}$ ) associadas a duas épocas de aplicação de nitrogênio em cobertura - NP, quando o nitrogênio em cobertura era aplicado na pastagem e NG, quando a aplicação no nitrogênio ocorria apenas na lavoura de grãos de milho anterior à pastagem. A área total de 14,2ha foi dividida em 12 piquetes (parcelas) com área variando de 1,1 a 1,5ha cada. Em anexo havia uma área de 5 ha para a manutenção dos animais reguladores e com o mesmo tipo de pastagem. Cada um dos três blocos era constituído por 4 piquetes (totalizando 12 piquetes), que alojavam um tratamento cada e foram ocupados com 3 animais teste por piquete e um número variável de animais reguladores dependente da distância entre a altura real do dossel e a altura pretendida. Desta forma, o método de pastejo usado foi lotação contínua com taxa de lotação variável (MOTT \& LUCAS, 1952). Neste experimento foram utilizados novilhos não castrados, produto do cruzamento entre as raças Charolês e Nelore, com aproximadamente 2 anos de idade e peso inicial de $263 \mathrm{~kg}$.

A aplicação com $\mathrm{N}$ representa a fertilização em nível de sistema, sendo aplicados $200 \mathrm{~kg}$ de $\mathrm{N}$ ha-1 em dose única (na forma de ureia - 45\% N) na pastagem ou no milho, anterior à pastagem. A fertilização com nitrogênio nos tratamentos NG foi aplicada em 13 de novembro de 2013 no estágio V6 do milho, enquanto nos tratamentos NP foi aplicada em 8 de maio de 2014, 35 dias após a semeadura da pastagem (início do perfilhamento). O total de nitrogênio aplicado por ha e por ano foi padrão em todos os tratamentos.

Os animais iniciaram o pastejo em 10/06/2014, quando a altura média da pastagem atingiu cerca de $30 \mathrm{~cm}$, sendo previamente pesados individualmente e identificados com brincos numerados. O término do pastejo, em que a pastagem teve os animais retirados para sua dessecação, foi no dia 10 de novembro de 2014, totalizando 163 dias de pastejo. A cada 15 dias a altura do pasto foi medida com uma régua graduada em centímetros, em 30 pontos das unidades experimentais e com base na média de altura era feito ou não o ajuste da carga animal. A altura média real do período experimental foi 24 e $11 \mathrm{~cm}$ para alta e baixa altura, respectivamente.

O ganho médio diário (GMD) foi obtido através da diferença entre o peso médio final e inicial dos animais testes, dividido pelo número de dias entre as pesagens dos animais. A carga animal (CA) consiste no total de quilograma de peso vivo mantido na unidade experimental num período de 28 dias (intervalo entre pesagens). Para o cálculo do ganho de peso por área (GPA), a CA foi dividida pelo peso vivo médio dos animais testes, multiplicado pelo GMD destes e dividido pela área da unidade experimental.

A estimativa da massa de forragem foi realizada a cada 28 dias coletando a forragem rente ao solo em cinco pontos em cada piquete, com o auxílio de um quadrado de $0,25 \mathrm{~m}^{2}$. As amostras foram pesadas e secas em estufa com ventilação forçada a $55^{\circ} \mathrm{C}$ por 72 horas. A oferta de forragem foi determinada pela média entre a massa de forragem inicial e final, dividida pela carga animal.

Foram realizadas duas avaliações de comportamento ingestivo (em 19 de julho de 2014 e em 29 de agosto de 2014) através da observação visual a cada 10 minutos, do nascer ao pôr-dosol. Os animais testes foram numerados com tinta alumínio nas duas laterais da região torácica para identificação a distância. As atividades de cada animal foram classificadas como: tempo diurno de pastejo (TDP) - atividade de procura, seleção e colheita da forragem, incluindo os curtos espaços de tempo utilizados no deslocamento para a seleção da dieta (HANCOCK, 1953); tempo diurno de ruminação (TDR) - período em que o animal esteve mastigando o bolo alimentar retornado do rúmen; e tempo diurno de outras atividades (TDO) - período em que o animal esteve interagindo socialmente, em deslocamento, descansando ou bebendo 
água (FORBES, 1988). A taxa de bocado foi mensurada contabilizando o tempo que cada animal levava para realizar 20 bocados (HODGSON, 1982), extrapolando para número de bocados por minuto (bocados minuto-1). Foram realizadas no mínimo dez avaliações de taxa de bocados, bem distribuídas ao longo do dia, por animal teste em cada avaliação de comportamento ingestivo.

A partir da observação do comportamento ingestivo dos animais, os avaliadores colheram manualmente espécies e partes de plantas semelhantes às consumidas, simulando assim o pastejo dos animais. Foram coletados durante a simulação do pastejo cerca de $0,35 \mathrm{~kg}$ de matéria verde que foram pré-secados em estufa de ventilação forçada a $55^{\circ} \mathrm{C}$ por 72 horas, moídos em moinho tipo Wiley com peneiras de $1 \mathrm{~mm}$ de diâmetro. As amostras foram analisadas no Laboratório de bromatologia da Unoesc, no Campus Xanxerê, onde foram determinadas a matéria seca (MS), matéria mineral (MM) e proteína bruta (PB) de acordo com a AOAC (1995).

Os dados foram submetidos à análise de variância por meio do procedimento MIXED do software estatístico SAS v.8.02 (SAS INSTITUTE, 2001). O período de avaliação foi utilizado como medida repetida no tempo a $5 \%$ de significância. As médias foram comparadas pelo teste de Tukey $(P<0,05)$.

\section{Resultados e discussão}

Houve interação entre os fatores estudados (altura do pasto e época de aplicação de nitrogênio) para as variáveis oferta de forragem ( $\mathrm{kg}$ de MS kg de peso vivo-1 $)(P=0,0002)$ e proteína bruta (\% PB) do pasto $(\mathrm{P}=0,0453)$ (Tabela 1$)$. $\mathrm{Na}$ altura de $10 \mathrm{~cm}$ o uso do $\mathrm{N}$ na pastagem fez com que a OF fosse aumentada, fato não ocorrido em $25 \mathrm{~cm}$. Quando a pastagem não foi fertilizada com $\mathrm{N}$ (NG), não houve diferença nas OF entre as alturas, já quando foi usado $\mathrm{N}$, a altura de $10 \mathrm{~cm}$ teve $O F$ maior que a de $25 \mathrm{~cm}$. A OF igual (NG) ou até superior (NP) para a menor altura do pasto em

Tabela 1. Interação entre os fatores altura do pasto e época de aplicação de nitrogênio para oferta de forragem ( $\mathrm{kg}$ de MS $\mathrm{kg}$ de peso vivo-1) e teores de proteína bruta (\%) da forragem Table 1. Interaction between sward height and nitrogen application time for forage supply ( $k g$ DM kg live weight-1) and forage crude protein content (\%)

\begin{tabular}{lllll}
\hline & \multicolumn{2}{c}{ Oferta de forragem } & \multicolumn{2}{c}{ Proteína Bruta } \\
& $10 \mathrm{~cm}$ & $25 \mathrm{~cm}$ & $10 \mathrm{~cm}$ & $25 \mathrm{~cm}$ \\
NG & $2,1 \mathrm{Ba}$ & $2,7 \mathrm{Aa}$ & $29,8 \mathrm{Aa}$ & $28,2 \mathrm{Ba}$ \\
NP & $5,0 \mathrm{Aa}$ & $3,2 \mathrm{Ab}$ & $30,0 \mathrm{Aa}$ & $30,5 \mathrm{Aa}$
\end{tabular}

NG - aplicação de nitrogênio na lavoura; NP - aplicação de nitrogênio na pastagem; $10 \mathrm{~cm}$ - pasto manejado a $10 \mathrm{~cm}$ de altura; $25 \mathrm{~cm}$ - pasto manejado a $25 \mathrm{~cm}$ de altura. Médias seguidas pela mesma letra maiúscula na coluna e minúscula na linha não diferem entre si pelo teste de Tukey a $5 \%$ de probabilidade.

relação à maior, é explicada pelo fato de que um pastejo muito intenso e de curta duração no NP-10cm fez com que a capacidade de suporte da pastagem posterior fosse deprimida, necessitando de um grande período de tempo com menor CA, fazendo com que o valor de OF fosse aumentado. Se a produção de forragem for deprimida e a partir daí tenta-se aumentar a altura, a CA deve ser diminuída e pode levar muito tempo com CA baixa, aumentando o valor de OF até que eleve sua MF, propiciando a situação de que tenhamos maior OF em menor altura de dossel.

O percentual de proteína bruta médio das coletas mensais mostrou-se muito semelhante em todos os tratamentos. Porém, houve um leve aumento no teor de PB (Tabela 1), na maior altura, quando a pastagem recebeu $\mathrm{N}$ em cobertura. Fato não ocorrido quando manejada em $10 \mathrm{~cm}$, provavelmente pela maior proporção de lâminas foliares na coleta de simulação do pastejo. Em maior altura de dossel há uma tendência de deposição de material morto, tecidos mais lignificados e de menor teor de $\mathrm{PB}$, sobretudo quando não fertilizada com $\mathrm{N}$ o dossel forrageiro pode diminuir levemente seu teor proteico, pela falta de disponibilidade de $\mathrm{N}$, em relação à pastagem que recebeu $200 \mathrm{~kg}$ de $\mathrm{N} \mathrm{ha}^{-1}$ no perfilhamento.

Não houve interação significativa entre os fatores estudados para ganho médio diário (GMD) $(P=0,5979)$, ganho de peso por área (GPA) $(P=0,1513)$ e carga animal (CA) $(P=0,1240)$. Estas variáveis também não foram influenciadas pela altura do pasto ( $P>0,05$; Tabela 2$)$, apresentando os valores médios de $0,985 \mathrm{Kg}$ animal dia-1; 301 e $814,5 \mathrm{Kg}$ de PV ha- ${ }^{-1}$ para GMD, GPA e CA, respectivamente. A CA e GPA foram influenciadas pela época de aplicação do nitrogênio ( $\mathrm{N}$ - grãos e $\mathrm{N}$ - pastagem; Tabela 2) ( $\mathrm{P}=0,0068 \mathrm{e}$ $P=0,0351$, respectivamente). $O G M D$ não foi influenciado pela época de aplicação de nitrogênio $(P=0,5255)$, pois mesmo sem a aplicação de $\mathrm{N}$ sobre a pastagem (NG), obteve-se alto teor proteico das amostras coletadas por simulação de pastejo (Tabela 1). Quanto às alturas de dossel, mencionam-se os valores de massa de forragem, que ao longo de 156 dias de pastejo e média de sete avaliações, para 25 e $10 \mathrm{~cm}$, foram de 2.425 e $2.020 \mathrm{~kg} \mathrm{MS} \mathrm{ha}^{-1}$, respectivamente. De forma diferente, foi constatado no trabalho de Kunrath et al. (2020) que, também em pastejo com lotação contínua e no mesmo tipo de pastagem, no uso da aveia-preta consorciada com azevém anual, o GMD foi maior quando o dossel foi mantido em $20 \mathrm{~cm}$ em relação a $10 \mathrm{~cm}$. As alturas reais, médias de avaliações semanais ao longo dos 156 dias de pastejo, foram de 24,13 e $11,36 \mathrm{~cm}$, respectivamente. Se analisarmos os resultados de intensidade de pastejo em azevém dos trabalhos que deram suporte ao conceito de pastoreio Rotatínuo encontra-se a recomendação que esta espécie deve ser manejada entre 11 e 18cm (SCHONS et al., 2021). 
No presente trabalho, além do azevém havia aveia-preta. Desta forma a altura recomendada deveria ser levemente superior a essa recomendação. No entanto, a maior contribuição na composição botânica do dossel foi de fato o azevém barjumbo e, por isso, pode-se inferir que a menor altura de dossel deste trabalho estaria dentro das recomendações atuais para maximizar a taxa de ingestão. Deste modo, provavelmente não houve limitação de consumo a $10 \mathrm{~cm}$ que induzisse a um menor desempenho. Conforme a Tabela 3, não houve efeito significativo dos fatores de tratamento para taxa de bocado, que tem relação inversa com massa de bocado (BOVAL \& SAUVANT, 2021). Portanto, mesmo na menor altura de dossel, o consumo dos animais não deve ter sido limitado. Deifeld et al. (2021), avaliando desempenho animal em outro ano do mesmo experimento, também não observaram diferenças significativas de GMD independentemente se a pastagem foi ou não adubada com N. Porém, ao contrário deste artigo, verificaram maior GMD para a maior altura de dossel (1,37 em $25 \mathrm{~cm}$, e $\left.1,11 \mathrm{~kg} \mathrm{an}^{-1} \mathrm{dia}^{-1} \mathrm{em} 10 \mathrm{~cm}\right)$. Assmann et al. (2010), estudando os efeitos da introdução de diferentes espécies de trevos (leguminosas) e da adubação nitrogenada em pastagem de aveias em sistema integrado de produção agropecuária, concluíram que a fertilização química é mais eficiente para manter a sustentabilidade de sistemas intensivos de elevada produtividade. Os autores verificaram GMD de $1,5 \mathrm{~kg}$ animal $\mathrm{dia}^{-1}$ com fertilização nitrogenada nas aveias, ou seja, 32\% maior que o tratamento em que as aveias foram consorciadas aos trevos e $41 \%$ maior que o tratamento controle (sem adubação e consórcio).

Em SIPA alto GMD é de suma importância, principalmente em locais onde as pastagens de inverno são utilizadas para fazer terminação de bovinos de corte. Num estudo em Campo Mourão, no Paraná, Turini et al. (2015), avaliando o desempenho produtivo e características de carcaça de bovinos mestiços $1 / 2$ Angus $1 / 2$ Nelore inteiros e castrados

Tabela 2. Valores médios para carga animal (CA, Kg de PV ha ${ }^{-1}$ ), ganho médio diário (GMD, Kg de PV animal dia-1) e ganho por área (GPA, kg de PV ha-1) nas diferentes épocas de aplicação de nitrogênio e alturas de manejo do pasto

Table 2. Average values for animal load (CA, $k g$ of $\left.P V h^{-1}\right)$, average daily gain (GMD, $k g$ of animal PV day ${ }^{-1}$ ) and gain per area (GPA, $\mathrm{kg}_{\text {of }} \mathrm{PV} \mathrm{ha} \mathrm{a}^{-1}$ ) at different nitrogen application periods and pasture management heights

\begin{tabular}{lccc}
\hline & CA & GMD & GPA \\
NG & $693 \mathrm{~B}$ & 0,95 & $257 \mathrm{~B}$ \\
\hline $\mathrm{NP}$ & $936 \mathrm{~A}$ & 1,01 & $346 \mathrm{~A}$ \\
\hline $10 \mathrm{~cm}$ & $\mathrm{CA}$ & $\mathrm{GMD}$ & $\mathrm{GPA}$ \\
\hline $25 \mathrm{~cm}$ & 870 & 0,91 & 298 \\
\hline
\end{tabular}

NG - aplicação de nitrogênio na lavoura; NP - aplicação de nitrogênio na pastagem; $10 \mathrm{~cm}$ - pasto manejado a $10 \mathrm{~cm}$ de altura; $25 \mathrm{~cm}$ - pasto manejado a $25 \mathrm{~cm}$ de altura. Médias seguidas pela mesma letra maiúscula na coluna e minúscula na linha não diferem entre si pelo teste de Tukey a $5 \%$ de probabilidade.

dentro de sistema integrado de produção agropecuária, obtiveram ganhos de peso diário de 0,89 e 0,70kg animal $\mathrm{dia}^{-1}$ para bovinos inteiros e castrados, respectivamente. No presente trabalho, a média de ganho de peso diário dos novilhos mestiços inteiros foi de $0,98 \mathrm{~kg}$ animal dia ${ }^{-1}$. Apesar de importante, o GMD não é alterado pelo aporte de $\mathrm{N}$ ao pasto de forrageiras hibernais (LUPATINI et al., 2013), mas por outros fatores de manejo, como intensidade de pastejo (KUNRATH et al., 2020) ou suplementação (VAZ et al., 2013).

A CA média de todo período experimental não foi diferente entre as alturas de pasto $(P=0,1129)$. No entanto, o pasto com $10 \mathrm{~cm}$ apresentou maior carga animal durante três períodos experimentais sendo que no segundo e terceiro período não apresentou maior carga que o manejo de $25 \mathrm{~cm}$, em consequência da grande carga animal exercida no primeiro período experimental onde a pastagem foi rebaixada intensamente e assim não conseguiu se recuperar ao longo de dois períodos de pastejo. Ressalta-se que a CA de cada período é mais dependente do manejo dos animais reguladores utilizados para corrigir a altura da pastagem do que as condições da pastagem dentro de cada período. Em relação ao $\mathrm{N}$, maior $\mathrm{CA}$ foi observada quando $200 \mathrm{~kg} \mathrm{ha}^{-1}$ de $\mathrm{N}$ foram aplicados na fase pastagem e não no milho, anterior à pastagem, a exemplo do ocorrido no experimento de Deifeld et al. (2021). Os tratamentos que receberam adubação nitrogenada na pastagem apresentaram carga animal de $936 \mathrm{~kg} \mathrm{PV} \mathrm{ha}^{-1}$, ou seja, $26 \%$ superior aos que receberam adubação nitrogenada apenas na fase de grãos ( $N$ - grãos) ( $P=0,0068)$. Incremento percentual idêntico ao encontrado por Deifeld et al. (2021) em que a CA na pastagem de aveia-preta sem adubação nitrogenada (quando somente a lavoura foi adubada) suportou uma CA média de $793 \mathrm{~kg}$ PV ha-1 e quando recebeu $\mathrm{N}$ em cobertura ( $200 \mathrm{~kg} \mathrm{ha}^{-1}$ ) a CA foi de $1.004 \mathrm{~kg}$ PV ha ${ }^{-1}$.

Analisando o GPA, não houve diferença significativa entre as alturas de dossel $(P=0,848)$ e sim entre os sistemas de adubação nitrogenada $(P=0,0351)$. $O$ $\mathrm{N}$ em cobertura na pastagem proporcionou acréscimo de $89 \mathrm{~kg} \mathrm{ha}^{-1}$ em relação aos piquetes de pastos não adubados e que receberam adubação nitrogenada apenas na lavoura ( $N$ - grãos). Devese chamar atenção para o fato de que o GMD não apresentou diferença significativa $(P=0,5255)$ e que o GPA foi maior nos tratamentos com adubação $(P=0,0351)$ devido a uma maior carga animal. Outros trabalhos científicos 
também confirmam o significativo efeito que a adubação nitrogenada das pastagens de inverno tem sobre o nível de produtividade animal por área (LUPATINI et al., 2013).

Tradicionalmente em SIPA fez-se aplicação de $\mathrm{N}$ na fase grãos com a expectativa de que o $\mathrm{N}$ residual desta aplicação fosse utilizado pela pastagem e consequentemente para a produção animal. Contudo, os dados deste trabalho indicam que a adubação nitrogenada na cultura de grãos não é ciclada para a pastagem em efetividade que promova alta produção animal por área. Provavelmente devido ao fato de que a exportação de nutrientes pela lavoura é muito maior que pelo produto animal, pois este mantém a maior parte dos nutrientes ciclando no sistema soloplanta-animal (FARIAS et al., 2020). Desta forma, torna-se essencial a adubação da pastagem em SIPA. O contrário seria verdadeiro, pesquisas realizadas por Sandini et al. (2011) e Maccari et al. (2021), estudando ciclagem de nutrientes da pastagem para a lavoura de grãos, concluem que a adubação nitrogenada quando realizada na pastagem de inverno ocasiona um incremento na produção de milho no verão, demonstrando assim que existe efeito "residual" da adubação nitrogenada feita na pastagem para a lavoura subsequente. Estes autores ainda comentam que a presença animal não interfere na produção de grãos.

Não foram observadas interações entre altura do pasto e época de aplicação de nitrogênio para as variáveis de comportamento animal $(P=0,4626$; 0,6723; 0,3034 e 0,6241 para TDP, TDR, TDO e TxBoc, respectivamente). Conforme a Tabela 3, as variáveis de comportamento ingestivo foram influenciadas pela altura do dossel e não pela presença ou ausência de adubação nitrogenada. O tempo diário de pastejo (TDP) foi maior para os animais mantidos nos piquetes de $10 \mathrm{~cm}(P=0,0190)$, sendo que apresentaram menor tempo diário de ruminação (TDR; $P=0,027)$. Soares et al. (2019) também verificaram relação linear negativa entre altura de dossel e TDP e negativa com TDR. Esses resultados indicam que os animais sobre dossel mantido a $10 \mathrm{~cm}$, em relação aos animais sobre dossel de $25 \mathrm{~cm}$, poderiam estar compensando uma possível menor taxa de ingestão, pois o aumento no TDP é uma estratégia que visa a não diminuição acentuada do consumo diário (AMARAL et al., 2012). Além disso, muito importante especialmente em SIPA, o maior TDP indica que os animais percorrem maior distância durante o dia, no seu processo de forrageamento (AMARAL et al., 2012). Manejo de menor altura de dossel, com menor massa de forragem e maior número de animais por ha, aumenta a probabilidade de compactação do solo (aumento de densidade e diminuição de macroporosidade).

A taxa de bocados (TxBoc) $(P=0,8622)$ e o tempo diário de outras atividades (TDO) ( $P=0,0531)$ não apresentaram diferenças significativas entre as alturas de pasto nem entre as épocas de adubação nitrogenada $(P=0,9932$ e 0,2337 para TxBoc e TDO, respectivamente), sendo que o valor médio obtido dos quatro tratamentos e nas duas datas de avaliação foi de 41 bocados por minutos e 172 minutos diários em outras atividades.

\section{Conclusão}

A adubação nitrogenada de um sistema integrado de produção agropecuária deve ser aplicada na fase pastagem, por incrementar a capacidade de suporte da pastagem, e, mesmo sem alterar o desempenho individual dos animais, promove maior produção animal por unidade de área.

\section{Referências}

AMARAL, M.F.; MEZZALIRA, J.C.; BREMM, C., TRINDADE, J. K.; GIBB, M.J.; SUÑE, R.W.M.; CARVALHO, P.C.F. Sward structure management for a maximum short-term intakerate in annual ryegrass. Grass and Forage Science, Hoboken, v.68, n.2, p.271-277, 2012. DOI: https://doi.org/10.1111/j.13652494.2012.00898.x.

ASSMANN, T.S.; ASSMANN, A.L.; ASSMANN, J.M.; SOARES, A.B.; BORTOLLI, M.A. Produção de gado de corte e de pastagem de aveia em sistema de integração lavoura-pecuária em presença e ausência de trevo e nitrogênio. Revista Brasileira de Zootecnia, Viçosa, v.39, n.7, p.1387-1397, 2010. DOI: https://doi. org/10.1590/S1516-35982010000700001.

ASSOCIATION OF OFFICIAL ANALYTICAL CHEMISTS - AOAC. Official methods of analysis. 16. ed. Washington, D.C.: Association of Official Analytical Chemists, INC, 1995.

BOVAL, M.; SAUVANT, D. Ingestive behaviour of grazing ruminants: Meta-analysis of the components linking bite mass to daily intake. Animal Feed Science and Technology, Amsterdã, v.278, 2021. Disponível em: https://www.researchgate.net/ publication/352764192_Ingestive_behaviour_of_grazing_ruminants_Meta-analysis_ of_the_components_linking_bite_mass_to_ 
daily_intake. Acesso em: 13 jul. de 2021. CARPINELLI, S.; FONSECA, A.F.; WEIRICH NETO, P.H.; DIAS, S.H.B.; PONTES, L.S. Spatial and temporal distribution of cattle dung and nutrient cycling in integrated crop-livestock systems. Agronomy, Basiléia, v.10, n.5, p.672, 2020. DOI: https://doi.org/10.3390/ agronomy10050672.

COMISSÃO DE QUÍMICA E FERTILIDADE DO SOLO - CQFSRS/SC. Manual de adubação e de calagem para os estados do Rio Grande do Sul e Santa Catarina. Porto Alegre: [s.n.], 2016.

COSTA, M.; SHIGAKI, F.; ALVES, B.; KLEINMAN, P.; PEREIRA, M. Swine manure application methods effects on ammonia volatilization, forage quality, and yield in the PreAmazon Region of Brazil. Chilean Journal of Agricultural Research, Chillán, v.74, n.3, p.311-318, 2014. DOI: http://dx.doi. org/10.4067/S0718-58392014000300009.

DEIFELD, F.L.C.; SOARES, A.B.; SCHMITT, A.; ASSMANN, T.S.; MISSIO, R.L.; ZATTA, A.C.; MENSOR, M.; CANDIOTTO, L.; BARRIGA, P.A.B.; CANDIOTTO, F. Grazing height and nitrogen fertilization strategy in black oat/ maize succession. Semina: Ciências Agrárias, Londrina, v.42, n.4, p.2539-2554, 2021. DOI: 10.5433/1679-0359.2021v42n4p2539

FARIAS, G.D.; DUBEUX, J.C.B.; SAVIAN, J.V.; DUARTE, L.P.; MARTINS, A.P.; TIECHER, T.; ALVES, L.A.; CARVALHO, P.C.F.; BREMM, C. Integrated crop-livestock system with system fertilization approach improves food production and resource-use efficiency in agricultural lands. Agronomy for Sustainable Development, Nova York, v.40, n.6, p.39, 2020. DOI: https://doi.org/10.1007/ s13593-020-00646-z.

FERRAZZA, J.M.; SOARES, A.B.; MARTIN, T.N; ASSMANN, A.L.; NICOLA, V. Produção de forrageiras anuais de inverno em diferentes épocas de semeadura. Revista Ciência Agronômica, Fortaleza, v.44, n.2, p.379389, 2013. Disponível em: http://ccarevista. ufc.br/seer/index.php/ccarevista/article/ view/1762 Acesso em: 18 jul. 2021.

FORBES, T.D.A. Researching the plant-animal interface: the investigation of ingestive behavior in grazing animals. Journal of Animal Science, Lexington, v.66, p.2369-2379, 1988. Disponível em: https://userweb. weihenstephan.de/lattanzi/Lit/Forbes\%20 1985.pdf. Acesso em: 19 nov. 2021.

HANCOCK, J. Grazing behaviour of cattle. Animal Breeding Abstract. Farnhan Royal, v.21, n.1, p.1-13, 1953.

HODGSON, J. Ingestive behavior. In: J. D. LEAVER (Ed.) Herbage Intake Handbook. Hurley: British Grassland Society, 1982. p.113.

KUNRATH, T.R.; NUNES, P.A.A.; de SOUZA FILHO, W.; CADENAZZI, M.; BREMM, C.; MARTINS, A.P., CARVALHO, P.C.F. Sward height determines pasture production and animal performance in a long-term soybean-beff cattle integrated system. Agricultural Systems, Amsterdã, v.177, p.102716, 2020. DOI: http://dx.doi.org/10.1016/j. agsy.2019.102716.

LUPATINI, G.C.; RESTLE, J.; VAZ, R.Z.; VALENTE, A.V.; ROSO, C.; VAZ, F.N. Produção de bovinos de corte em pastagem de aveia preta e azevém submetida à adubação nitrogenada. Ciência Animal Brasileira, Goiânia, v.14, n.2, p.164-171, 2013. Disponível em: https:// www.revistas.ufg.br/vet/article/view/21068

MACCARI, M.; ASSMANN, T.S.; BERNARDON, A.; SOARES, A.B.; FRANZLUEBBERS, A.; de BORTOLLI, M.; de BORTOLLI, B.B.; GLIENKE, C.L. Relationships between N, $P$, and $K$ in corn biomass for assessing the carryover effects of winter pasture to corn. European Journal of Agronomy, Amsterdã, v.129, p.126317, 2021. DOI: http://doi. org/10.1016/j.eja.2021.126317

Mc NAUGHTON, S.J. Compensatory plant growth as a response to herbivory. Oikos, Copenhague, v.40, p.329-336, 1983. Disponivel em: https://www.jstor.org/stable/3544305. Acesso em: 19 nov. 2021.

MOTT, G.O.; LUCAS, H.L. The design conduct and interpretation of grazing trials on cultivated and improved pastures. In: International Grassland Congress, 6., 1952. Proceedings[...] Pennsylvania: State College Press, p.1380 - 1395, 1952.

PETERSON, C.A.; DEISS, L.; GAUDIN, A.C.M. Commercial integrated crop-livestock systems achieve comparable crop yields to specialized production systems: A metaanalysis. PLoS ONE, São Francisco, v.15, n.5, e0231840, 2020. DOI: https://doi. org/10.1371/journal.pone.0231840.

SANDINI, I.E.; MORAES, A., PELISSARI, A.; NEUMANN, M.; FALBO, M.K.; NOVAKOWISKI, J.H. Efeito residual do nitrogênio na cultura do milho no Sistema de produção integração lavoura-pecuária. Ciência Rural, Santa Maria, v.41, n.8, p.1315-1322, 2011. DOI: https://doi.org/10.1590/S010384782011005000099.

SCHONS, R.M.T.; LACA, E.A.; SAVIAN; J.V.; MEZZALIRA, J.C.; SCHNEIDER, E.A.N.; CAETANO, L.A.M.; ZUBIETA, A.S.; BENVENUTTI, M.A.; CARVALHO, P.C.de F. "Rotatinuous" stocking: An innovation in grazing management to foster both herbage and animal production. Livestock Science, v.245, p.104406, 2021. Disponível em:

ht t ps:// w w w. sciencedirect. com/science/article/abs/pi / S1871141321000147?via\%3Dihub. Acesso em: 19 nov. 2021.

SOARES, A.B.; MIGLIORINI, F.; PITTA, C.S.R.; HILL, J.A.G.; da SILVEIRA, A.L.F.; SCHMITT, D. Estrutura de dossel e comportamento ingestivo de caprinos em pastos de papuã manejados sob lotação contínua. Ciência Animal Brasileira, Goiânia, v.20, p.1-13, 2019. DOI: https://doi.org/10.1590/18096891v20e-49219.

STATISTICAL ANALYSIS SYSTEM - SAS. Statistical analysis system user's guide Version 8.02. Cary: Statistical Analysis System Institute, 2001.

TURINI, T.; RIBEIRO, E.D.A.; ALVES, S.J.; MIZUBUTI, I.Y. e SILVA, L. Performance of intact and castrated beef cattle in an intensive crop pasture rotation system. Semina: Ciências Agrárias, Londrina, v.36, n.3, Suppl. 1, p.2339-2351, 2015. DOI: $\quad$ http://dx.doi.org/10.5433/16790359.2015v36n3Supl1p2339.

VAZ, R.Z.; LOBATO, J.F.P.; PACHECO, P.S. Performance of Braford steers grazing on cultivated pastures and fed or not fed an energy supplement. Revista Brasileira de Zootecnia, Viçosa, v.42, n.2, p.130-136, 2013. DOI: https://doi.org/10.1590/S151635982013000200008. 